\title{
Variability of Carabidae in time and space in open areas
}

\author{
Axel Schwerk, Pawel Salek, Mariusz Duszczyk, Michael Abs \& Jan Szyszko
}

Schwerk, A., Sałek, P., Duszczyk, M., Abs, M. \& Szyszko, J. 2006: Variability of Carabidae in time and space in open areas. - Entomol. Fennica 17:258-268.

The temporal and spatial variability of carabid fauna was studied on a colliery spoil heap area in Germany and on an area of post-agricultural soil in Poland using pitfall traps. Applying Mean Individual Biomass (MIB) of carabids as an indicator of environmental quality, all plots were assessed as being young stages of succession. Species richness and total carabid abundance fluctuated remarkably among different plots and study years. Total numbers of individuals fluctuated significantly in time, whereas species richness remained strikingly constant. The Jaccard's index of species similarity was low for the level of individual sampling plots but high for the total catches when comparing different years. Individual species showed asynchronicity of fluctuations in numbers of individuals at the level of individual plots. Based on these results we suggest that the observed patterns can be explained by the 'spreading of risk' hypothesis.

A. Schwerk, Warsaw Agricultural University, Laboratory of Evaluation and Assessment of Natural Resources, Nowoursynowska Street 166, 02-787 Warsaw, Poland.Email: aschwerk@yahoo.de

P. Salek, Warsaw Agricultural University, Laboratory of Evaluation and Assessment of Natural Resources, Nowoursynowska Street 166, 02-787 Warsaw, Poland.Email: pawelsalek@o2.pl

M. Duszczyk, Warsaw Agricultural University, Laboratory of Evaluation and Assessment of Natural Resources, Nowoursynowska Street 166, 02-787 Warsaw, Poland.Email: maniekd@o2.pl

M. Abs, Elßholzstrasse 8, D-10781 Berlin, Germany. Email: michael.abs @snafu.de

J. Szyszko, Warsaw Agricultural University, Laboratory of Evaluation and Assessment of Natural Resources, Nowoursynowska Street 166, 02-787 Warsaw, Poland.Email: jan.szyszko@wp.pl

Received 14 December 2005, accepted 23 April 2006

\section{Introduction}

Variability in time and space is a natural attribute of animal populations. Different metapopulation models aim at explaining such population dynamics (Hanski \& Gilpin 1991, den Boer \& Reddingius 1996). These models assume that the whole population (metapopulation) is composed of several subpopulations. Den Boer (1977) introduced the term 'interaction group' for 'groups of individuals living in places with spatial dimensions that do not substantially exceed the distances normally covered by the individuals in the relevant patterns of activity". However, if the 
spatial dimensions substantially exceed these distances, one will have to deal with 'subpopulations', i.e. 'interaction groups' that gradually merge into other ones (den Boer 1977). Metapopulation models are of basic interest for conservation biology (e.g., Hanski 1998), but also with respect to economic aspects (e.g. pest insects).

On degraded areas, such as intensively altered agricultural landscapes, an improvement of the habitat conditions is often required to restore or maintain animal and plant communities, especially in remaining fragments of 'original habitat'. According to succession models, careful management of the early stages of succession is important with respect to the future development and faunal and floral post-disturbance recovery of a given area subjected to restoration (e.g., Bradshaw 1984, Tilman 1987, Jochimsen 2001). To carry out these efforts in an ecologically sound way, knowledge about population dynamics on open areas representing young stages of succession is obviously necessary.

In the present paper, we analyse the variability of carabid beetles (Coleoptera: Carabidae) in time and space on open areas that have been degraded to a relatively high degree. Our data were elaborated using pitfall trapping in a long-term study project on a colliery spoil heap area in western Germany and on a former agricultural area in western Poland. We aim at answering the following questions.

(1) Do carabids show variability in space? Here, variability of species will be expressed by differences in total numbers at each sampling plot and differences in species similarity among multiple plots. The variability of individuals, on the other hand, will be expressed by differences in total numbers at each plot and in numbers of caught specimens of individual species among these plots.

(2) Do carabids show variability in time? Variability of species will be expressed by the degree of changes in species richness and in similarity of species composition among study years. Variability in the total catch and in abundance of individual species, on the other hand, will be expressed by measuring differences among study years. Moreover, these fluctuations may be assessed with respect to the degree of synchronicity among the sampling plots. In the present paper, fluctuations in catches of three species [the frequently-caught Poecilus versicolor (Sturm, 1824) and Calathus melanocephalus (Linné, 1758), and the rare Amara praetermissa (C. R. Sahlberg, 1827)] will be analysed.

(3) Is there spatial and temporal variation in carabid assemblage structure among successional stages? To understand variability in time in particular, an assessment of the stage of succession is important. This variability can be estimated by calculating the Mean Individual Biomass (MIB) of carabids at the studied sites over multiple years, or across different-aged, regenerating areas. The method assumes an ongoing process of succession with which the MIB of carabids increases (Szyszko et al. 2000). Theoretically, the biomass of a carabid may range from about $1 \mathrm{mg}$ [Dyschirius globosus (Herbst, 1784)] to over 1,500 mg (Carabus coriaceus Linné, 1758). In reality, MIB values range from about $40 \mathrm{mg}$ to about 400 mg (e.g., Szyszko et al. 1996, 2000), with some exceptional values falling beyond these extremes. MIB values close to $40 \mathrm{mg}$ (i.e., values below $100 \mathrm{mg}$ ) have been suggested to indicate young stages of succession (Szyszko et al. 1996, 2000). Here, spatial variability in stages of succession will be indicated by the variability in MIB among multiple traps, whereas temporal variability of successional stages will be indicated by differences in MIB values among different years of study. In this context we assume that an increase of MIB indicates the process of succession.

\section{Material and methods}

\subsection{Study areas and collecting methods}

Carabids were collected within the frame of an interdisciplinary research project on the Waltrop colliery spoil heap in the Ruhr Valley Area, western Germany (Vuong 1989) from 1989 to 2000. The aims of this project were to study the succession on different parts of the heap and to evaluate different methods of re-cultivation (e.g., Schwerk et al. 2004). Beetles were collected using pitfall traps (mouth diameter $12 \mathrm{~cm}$, concentrated sodium chloride solution as killing agent; a roof in- 
stalled a few $\mathrm{cm}$ above each trap). Altogether 24 pitfall traps were installed on the heap and its surroundings, 18 of which were placed at open areas. These traps covered different parts of the colliery spoil heap (traps 1-12), fallow ground (traps 1618), and former mining areas of Waltrop (traps 22-24). The traps 1-9 and 22-24 were arranged to grids with a distance of $50 \mathrm{~m}$ from each other. Traps 10-12 were located $50 \mathrm{~m}$ from each other but $100 \mathrm{~m}$ from the nearest other grid, whereas traps 16-18 were located $50 \mathrm{~m}$ from each other but $30 \mathrm{~m}$ from the nearest other grid. Below we analyse data from 1991-1994, 1996, and 2000, because during these years the 18 traps placed on open areas were used. Sampling covered the period from mid-March to early November, with the exceptions of 1996, with sampling from midApril, and of 2000, with sampling ending by the end of November.

We also used data from another study done in Poland. This study, done in the research field object "Krzywda" in Tuczno, was initiated in 2004. In this project, 53 pitfall traps were installed on former agricultural soils that had been fallow for about 10 years; 46 of the 53 traps were placed at open areas. Glass jars, with a funnel (mouth 10 $\mathrm{cm}$, bottom opening $1.6 \mathrm{~cm}$ ) attached to the mouth of each jar, were sunk in the ground flush with the soil surface. A roof was installed a few $\mathrm{cm}$ above the funnel. Ethylene glycol was used as trapping fluid.

These traps were placed forming a grid with seven columns (A-G) and seven rows (2-8). The columns were $100 \mathrm{~m}$ apart, while the rows were $50 \mathrm{~m}$ apart, with the exception of row 2 that was $70 \mathrm{~m}$ from row 3 . The micro-sites (= immediate surroundings of individual traps) varied with respect to management type and soil moisture conditions. Rows 2 and $4-8$ were infrequently mown and row 3 was frequently mown, without and with biomass removal, respectively. Traps A6, B7, C8 were located in wet habitat. Sampling covered the period from mid-May to mid-September in 2004.

At the Polish (Krzywda) sampling site, additional data - used in this paper - were collected prior to the initiation of the 2004 project. During the summers of 2001-2003, the population dynamics of $P$. versicolor was studied at the location of the trap A3. However, during these three years, sampling efficiency was increased using fences, and these data are thus not comparable with the results from 2004.

\subsection{Data analyses}

Carabids were determined to species level. Nomenclature follows Freude et al. (2004). Due to the fact that the sibling species Trechus quadristriatus (Schrank, 1781) and Trechus obtusus Erichson, 1837 were not distinguished every year of the study, these species were pooled for analytical purposes.

Similarities in species composition were assessed using Jaccard's (1902) index of species similarity. To assess the spatial variability for each study year at the Waltrop and Krzywda study areas, all possible pair-wise similarities among the traps were calculated. With respect to variability in time for each trap and the total catch in the respective years at the Waltrop study area, all possible pair-wise similarities among the study years were calculated. Data sets were tested for differences using non-parametric KruskalWallis test, followed by pair-wise comparisons using Mann-Whitney $U$ tests with sequentially rejective Bonferroni correction of significance levels (Holm 1979). Temporal variability was also analysed concerning similarities between consecutive years compared to longer time scales.

The data were categorized with respect to time span (number of years) among the compared samples, ranging from one year (e.g., $1991 \mathrm{com}-$ pared to 1992) up to nine years (1991 compared to 2000). Categorization was done for each single trap, as well as for the total carabid catch collected in the respective years. Data for single traps were subsequently pooled for each category. The median values for the categories were tested on correlations with increasing time span using Spearman rank correlation coefficient (Sachs 1984).

Numbers of species, numbers of individuals, and MIB values for the single traps as well as for the whole study area were tested for correlations with time using Spearman rank correlation coefficient.

MIB of carabids was calculated according to 
Table 1. Numbers of species, individuals, and Mean Individual Biomass values (MIB; in mg) for each pitfall trap (1-12, 16-18, 22-24) in Waltrop. Correlations with time (Spearman rank correlation coefficient): ${ }^{*}=p<0.05,{ }^{* *}=p<0.01,{ }^{* * *}=p<0.001$.

\begin{tabular}{|c|c|c|c|c|c|c|c|c|c|c|c|c|c|c|c|c|c|c|c|}
\hline \multicolumn{20}{|c|}{ Species } \\
\hline & $1^{*}$ & $2^{* * *}$ & 3 & 4 & 5 & 6 & 7 & $8^{*}$ & 9 & 10 & 11 & 12 & 16 & 17 & 18 & 22 & 23 & 24 & Tota \\
\hline 1991 & 12 & 17 & 14 & 13 & 19 & 19 & 11 & 18 & 17 & 8 & 16 & 7 & 26 & 20 & 29 & 15 & 26 & 13 & 56 \\
\hline 1992 & 19 & 16 & 17 & 16 & 17 & 19 & 14 & 13 & 22 & 10 & 18 & 9 & 31 & 34 & 33 & 17 & 24 & 15 & 55 \\
\hline 1993 & 7 & 10 & 10 & 12 & 12 & 12 & 11 & 16 & 15 & 6 & 10 & 10 & 12 & 14 & 11 & 6 & 11 & 5 & 48 \\
\hline 1994 & 8 & 9 & 10 & 18 & 15 & 16 & 12 & 16 & 16 & 12 & 18 & 7 & 19 & 16 & 19 & 13 & 12 & 10 & 55 \\
\hline 1996 & 2 & 9 & 5 & 10 & 13 & 14 & 7 & 12 & 12 & 7 & 13 & 3 & 22 & 21 & 26 & 17 & 19 & 18 & 51 \\
\hline 2000 & 6 & 8 & 10 & 17 & 12 & 14 & 11 & 8 & 16 & 8 & 11 & 4 & 12 & 22 & 9 & 11 & 13 & 15 & 49 \\
\hline
\end{tabular}

\begin{tabular}{|c|c|c|c|c|c|c|c|c|c|c|c|c|c|c|c|c|c|c|c|}
\hline \multicolumn{20}{|c|}{ Individuals } \\
\hline & $1^{*}$ & $2^{* *}$ & $3^{* * *}$ & $4^{*}$ & $5^{*}$ & $6^{*}$ & $7^{* *}$ & $8^{* *}$ & $9^{* * *}$ & 10 & 11 & $12^{* *}$ & 16 & 17 & 18 & 22 & 23 & & Total $^{*}$ \\
\hline 991 & 195 & 69 & 100 & 206 & 124 & 321 & 160 & 167 & 138 & 33 & 308 & 95 & 87 & 311 & 99 & 65 & 168 & & 2,710 \\
\hline 1992 & 223 & 61 & 94 & 371 & 119 & 217 & 130 & 142 & 103 & 74 & 361 & 74 & 395 & 413 & 331 & 88 & 221 & & 3,510 \\
\hline 1993 & 44 & 48 & 46 & 145 & 52 & 63 & 118 & 104 & 96 & 46 & 83 & 76 & 73 & 177 & 20 & 18 & 12 & & 1,245 \\
\hline 199 & 40 & 52 & 20 & 112 & 65 & 92 & 88 & 107 & 72 & 60 & 259 & 31 & 90 & 65 & 32 & 76 & 60 & & 1,359 \\
\hline 1996 & 5 & 29 & 16 & 26 & 35 & 67 & 25 & 34 & 35 & 12 & 69 & 15 & 48 & 56 & 98 & 54 & 60 & 48 & 732 \\
\hline 2000 & 23 & 9 & 13 & 76 & 41 & 45 & 40 & 22 & 29 & 12 & 126 & 8 & 26 & 56 & 23 & 71 & 102 & 60 & 782 \\
\hline \multicolumn{20}{|c|}{ MIB (mg) } \\
\hline & 1 & 2 & 3 & 4 & 5 & 6 & $7^{* *}$ & 8 & 9 & 10 & 11 & 12 & 16 & 17 & 18 & 22 & 23 & 24 & Total \\
\hline 1991 & 56.3 & 39.3 & 49.5 & 51.4 & 34.7 & 44.5 & 37.1 & 37.2 & 53.9 & 63.5 & 60.3 & 49.7 & 18.5 & 27.5 & 43.9 & 86.0 & 67.2 & 76.0 & 47.6 \\
\hline 1 & 69.2 & 38.1 & 44.6 & 54.4 & 36.2 & 44.1 & 46.3 & 55.6 & 52.8 & 83.2 & 59.2 & 60.3 & 43.5 & 57.5 & 60.1 & 89.5 & 49.7 & 86.1 & 55.6 \\
\hline 1993 & 58.7 & 16.5 & 55.0 & 61.4 & 40.3 & 58.0 & 48.1 & 58.3 & 58.7 & 78.8 & 67.3 & 73.2 & 51.8 & 36.5 & 61.5 & 59.4 & 32.2 & 143.1 & 54.9 \\
\hline 1994 & 64.0 & 42.7 & 39.3 & 68.6 & 40.3 & 53.6 & 64.0 & 54.6 & 43.5 & 66.6 & 67.9 & 54.8 & 59.0 & 50.5 & 55.9 & 76.9 & 66.5 & 151.9 & 61.3 \\
\hline 1996 & 61.4 & 42.7 & 64.1 & 62.9 & 41.9 & 62.4 & 55.5 & 52.8 & 74.9 & 73.8 & 56.0 & 72.3 & 101.4 & 79.0 & 80.3 & 82.2 & 71.6 & 100.1 & 71.3 \\
\hline 2000 & 9.8 & 78.6 & 49.0 & 53.7 & 33.0 & 54.5 & 69.0 & 60.6 & 64.7 & 75.5 & 51.2 & 62.1 & 48.5 & 36.0 & 45.0 & 75.9 & 78.5 & 94.6 & 60.8 \\
\hline
\end{tabular}

Szyszko (1983), i.e., using a formula that expresses the relation between body length $(x)$ and biomass $(y)$ :

$\ln y=-8.92804283+2.5554921 \ln x$

For the calculations of MIB values, the biomass of the individuals caught were summed and subsequently divided by the total number of the individuals for the respective sample.

\section{Results}

Altogether 10,338 individuals belonging to 79 species were collected in the Waltrop area (Appendix). In the Krzywda area, 2,235 individuals belonging to 71 species were collected in 2004 (Appendix) and 336 individuals of $P$. versicolor during 2001-2003. The results concerning spe-

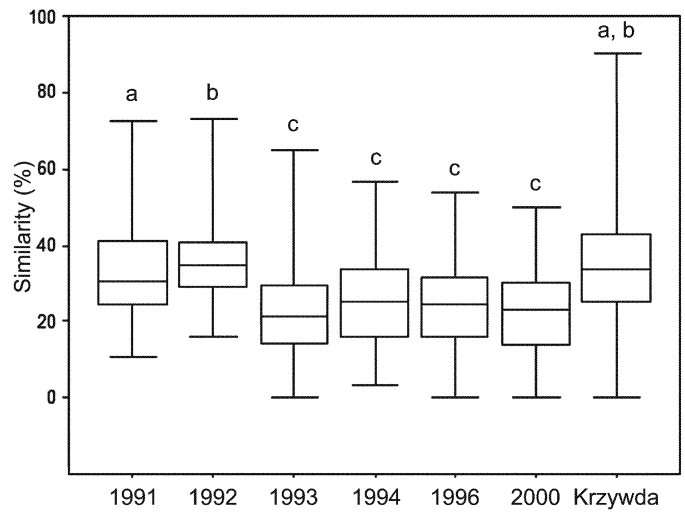

Fig. 1. Box-whisker plots (median, quartiles and $\mathrm{min} / \mathrm{max}$ ) for the distributions of Jaccard's index of species similarity for pair-wise comparisons among individual traps in Waltrop and in Krzywda (2004 only; box plot "Krzywda"). Kruskal-Wallis test, $p<0.001$; lower-case letters $(a, b, c)$ indicate statistically significant differences (Mann-Whitney $U$ tests with Bonferroni correction). 
Table 2. Numbers of species, individuals, and Mean Individual Biomass values (MIB; in $\mathrm{mg}$ ) for each pitfall trap (columns A-G, rows 2-8) in Krzywda.

\begin{tabular}{|c|c|c|c|c|c|c|c|}
\hline & A & B & C & $\begin{array}{c}\text { Species } \\
\text { D }\end{array}$ & $E$ & $\mathrm{~F}$ & G \\
\hline 8 & - & - & 13 & 12 & 10 & 13 & 12 \\
\hline 7 & - & 8 & 12 & 13 & 11 & 13 & 10 \\
\hline 6 & 5 & 9 & 10 & 11 & 12 & 14 & 11 \\
\hline 5 & 9 & 19 & 8 & 10 & 7 & 11 & 8 \\
\hline 4 & 13 & 20 & 10 & 10 & 11 & 17 & 8 \\
\hline 3 & 15 & 17 & 12 & 8 & 16 & 16 & 16 \\
\hline \multirow[t]{3}{*}{2} & 10 & 10 & 10 & 15 & 14 & 6 & 7 \\
\hline & & & & Individuals & & & \\
\hline & A & B & C & $\mathrm{D}$ & E & $F$ & G \\
\hline 8 & - & - & 56 & 36 & 20 & 37 & 57 \\
\hline 7 & - & 60 & 59 & 87 & 35 & 26 & 37 \\
\hline 6 & 13 & 18 & 48 & 41 & 62 & 49 & 33 \\
\hline 5 & 45 & 80 & 61 & 63 & 22 & 35 & 77 \\
\hline 4 & 34 & 132 & 29 & 35 & 37 & 112 & 25 \\
\hline 3 & 56 & 111 & 32 & 56 & 57 & 82 & 63 \\
\hline \multirow[t]{3}{*}{2} & 21 & 24 & 37 & 59 & 43 & 11 & 22 \\
\hline & & & & MIB (mg) & & & \\
\hline & $A$ & B & C & D & $E$ & $\mathrm{~F}$ & G \\
\hline 8 & - & - & 158.9 & 49.9 & 49.1 & 47.0 & 47.9 \\
\hline 7 & - & 177.8 & 125 & 68.6 & 83.7 & 52.8 & 81.5 \\
\hline 6 & 124.9 & 62.1 & 109.5 & 61.2 & 89.0 & 51.7 & 68.2 \\
\hline 5 & 123.6 & 78.9 & 49.9 & 78.6 & 64.4 & 63.0 & 55.2 \\
\hline 4 & 50.6 & 71.5 & 74.2 & 96.3 & 116.2 & 51.8 & 52.4 \\
\hline 3 & 62.8 & 44.2 & 38.5 & 44.9 & 50.0 & 44.6 & 56.6 \\
\hline 2 & 60.5 & 66.7 & 64.6 & 59.8 & 51.6 & 60.2 & 79.0 \\
\hline
\end{tabular}

cies, individuals, and MIB values are shown in Tables 1 and 2, respectively.

Both study areas showed a high spatial variability in species numbers. At the Waltrop study area, the traps 16, 17 and 18 (located on fallow ground) produced higher values than the other traps. However, compared with the total numbers of species, species numbers collected by individual traps were low. The median species similarities, as measured using Jaccard's index, among the Waltrop traps ranged from 21.43 to 34.78 for the different years. At the Krzywda study area, on the other hand, a median value of 33.33 was obtained. Significant differences between the datasets were found (Kruskal-Wallis test, $p<0.001$; Fig. 1). The distributions among the different years also differed significantly at the
Waltrop study area. The distribution of species similarities at the Krzywda study area did not significantly differ from the distributions found at the Waltrop study area in 1991 and 1992. Moreover, the total catch and the abundances of individual species varied remarkably in space in both study areas.

The temporal variability could be traced at the Waltrop study area. Here, the species richness fluctuated remarkably at the level of individual traps among the years. The traps 1, 2 and 8 showed a significant decrease in species richness with time (Table 1). Contrary to the individual trap level, the total species richness collected per year at the Waltrop study area was strikingly constant. There was no tendency toward an increase or a decrease in the total carabid catch (Table 1). 
Table 3. Median values of Jaccard's index of species similarity for pair-wise comparisons among samples categorized with respect to time span (number of years) among the compared samples for the spatial level of individual traps and the total number of species collected in Waltrop. Significant correlations with time are indicated (Spearman rank correlation coefficient): ${ }^{* *}=p<0.01$.

\begin{tabular}{lrr}
\hline $\begin{array}{l}\text { Time span } \\
\text { (years) }\end{array}$ & $\begin{array}{c}\text { Single } \\
\text { traps }^{* *}\end{array}$ & $\begin{array}{r}\text { Total no. } \\
\text { species }\end{array}$ \\
\hline 1.00 & 42.50 & 70.00 \\
2.00 & 36.55 & 67.70 \\
3.00 & 33.95 & 66.60 \\
4.00 & 35.95 & 66.70 \\
5.00 & 31.05 & 64.60 \\
6.00 & 27.55 & 62.50 \\
7.00 & 25.65 & 64.40 \\
8.00 & 30.50 & 68.80 \\
9.00 & 30.70 & 61.50 \\
\hline
\end{tabular}

Calculations of species similarities (Jaccard's index) among study years generally indicated low values with high variability for the spatial level of individual traps when compared to the species similarities calculated for the total of species collected in the respective years (KruskalWallis test, $p<0.001$; Fig. 2). The distribution of species similarities for the total area differed significantly from the distributions for the individual traps. The majority of the distributions for the individual traps did not significantly differ from each other, however. The analysis of the species similarities with respect to time span (number of years) among the samples (Table 3) indicated a slight decrease in species similarity values with increasing time span for the individual traps. Elevated values were found, particularly concerning species similarities for the individual traps in consecutive years (one-year time span). The similarity measure did not significantly correlate with increasing time span over the total area.

Numbers of individuals collected with the individual traps fluctuated strongly among the years. There were also notable differences in total numbers of individuals. Contrary to the species numbers, the numbers of individuals showed a significant decrease in the run of the study at $>50 \%$ of the traps, particularly at those placed on the colliery spoil. As a result, the total number of

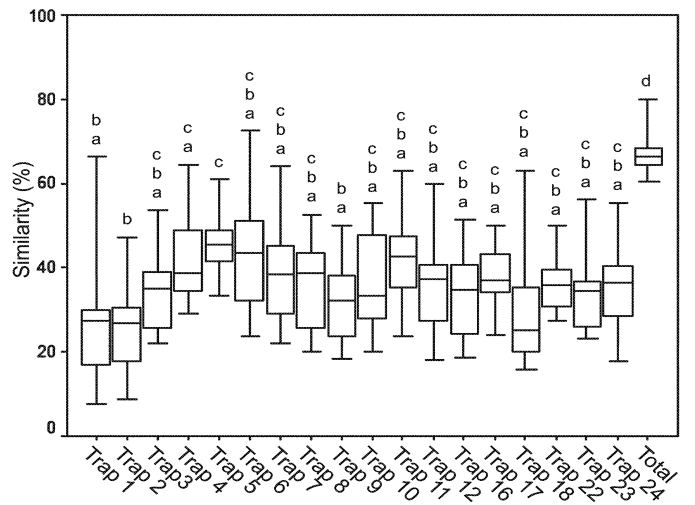

Fig. 2. Box-whisker plots (median, quartiles, $\min / \max$ ) for the distributions of Jaccard's index of species similarity for pair-wise comparisons among study years for individual traps (Trap 1-24) and the total number of species (Total) collected in Waltrop. Kruskal-Wallis test, $p<0.001$; lower-case letters (a, b, c, d) indicate statistically significant differences (Mann-Whitney $U$ tests with Bonferroni correction).

individuals collected in individual years decreased significantly (Table 1 ).

Figs. 3-4 show the fluctuations in total numbers and in numbers of individual traps for $P$. versicolor and $C$. melanocephalus. For the sake of clarity, only the ten traps with highest numbers of individuals are depicted for each species below. These 10 traps accounted for $91.1 \%$ of all collected individuals of $P$. versicolor and 97.4\% in the case of $C$. melanocephalus. Both species fluctuated remarkably in time and space. However, the degree of asynchronicity in fluctuations among individual traps was far more pronounced for $P$. versicolor as compared to $C$. melanocephalus. Strong fluctuations in numbers of individuals of $P$. versicolor were also observed at plot A3 of the Krzywda study area among 2001 (133 individuals), 2002 (198 individuals), and 2003 (5 individuals).

Only 40 individuals of $A$. praetermiss $a$ were collected during the study. These individuals were spread over ten different traps, among which the catches varied remarkably among the years. However, the species was not found in only one year (1996).

With only a few exceptions, the MIB values ranked below $100 \mathrm{mg}$ in both study areas. Only one of the traps at Waltrop study area showed a significant tendency toward an increase of MIB 

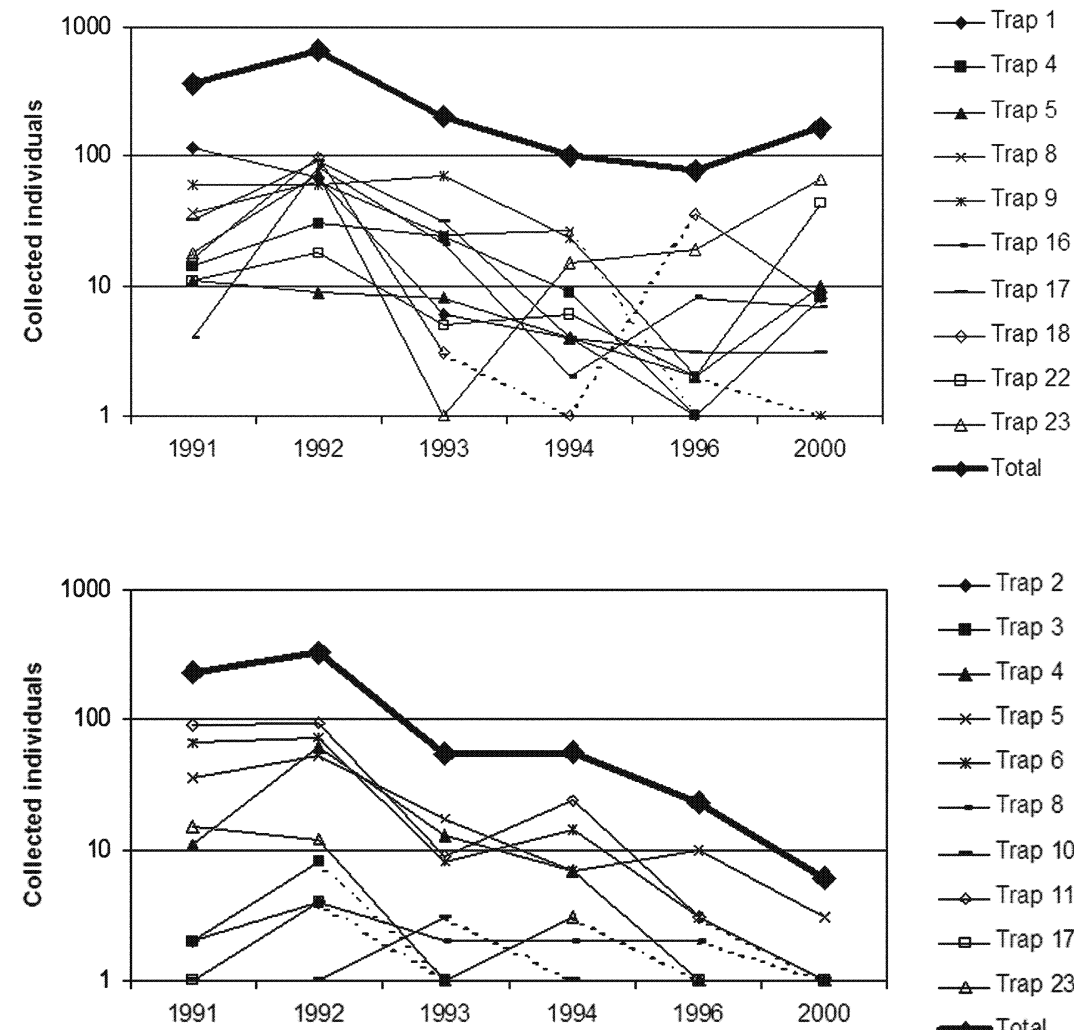

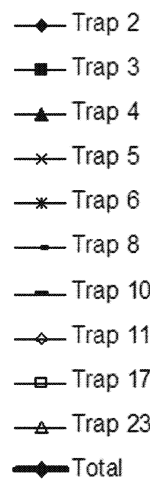

Fig. 3. Fluctuations in total numbers (bold line) and numbers at individual traps (thin lines) of Poecilus versicolor, Waltrop data. Dotted lines connect zero and non-zero samples.
Fig. 4. Fluctuations in total numbers (bold line) and numbers at individual traps (thin lines) of Calathus melanocephalus; Waltrop data. Dotted lines connect zero and non-zero samples. in time. With respect to the MIB values calculated for the whole area, no significant increases with time were observed (Table 1).

\section{Discussion}

The results indicated high temporal and spatial variability both in terms of species richness and the total carabid catch at the spatial level of individual traps. With respect to variability in time, significant variability was observed in the total catch in Waltrop, whereas data on species were less variable (study questions 1-2). The study areas were apparently characterized by young stages of succession, as reflected by their carabid faunas. The MIB values did not indicate remarkable changes in stages of succession (study question 3).

The high overall numbers of species in Waltrop and Krzywda apparently resulted from the spatial variability of carabid species. This result may be explained only partly by differences in the ecological characteristics of the plots. For example, in Waltrop, the traps 16, 17 and 18 (located on fallow ground) contributed significantly to the total number with exclusive species. Similarly, at the Krzywda study area traps A6, B7, and C8 (located in wet habitat) produced several exclusive species. However, plots of similar ecological characteristics may often show differences in species composition (e.g., Magura 2002, Hatteland et al. 2005). Moreover, in the present study species found exclusively in one trap in a given year could be found solely in other traps in the subsequent years.

With respect to interpreting temporal patterns of carabids, succession has to be taken into account, because the process involves a replacement of species characteristic for earlier stages of succession by species typical for later ones (e.g., Neumann 1971, Bradshaw 1984). According to Szyszko et al. (2000), the low MIB values on the plots of the present study indicate young stages of succession on both study areas. Moreover, the results at the Waltrop study area indicated that the 
stage of succession on the individual traps remained relatively stable. However, there was a slight decrease in species similarities with increasing time span among the samples of the individual plots, particularly due to an elevated value for consecutive years. This result may be explained by over-wintering behaviour of carabids. To conclude, successional processes in our study explained the changes in species composition only very little.

The comparatively low similarities in species composition among individual traps indicate a high turnover of species at these sites. Rare species in the study area apparently only occasionally appeared at some of the plots. In contrast, the high species similarities over the whole study area indicate low species turnover rates. The probability of extinction for the studied species is presumably low. We suggest that rare species, such as $A$. praetermissa, occur in low numbers but regularly on the whole study areas.

Assuming that the level of individual traps in the present study represented 'subpopulations' in the sense of den Boer (1977), the observed richness patterns at various spatial and temporal levels may be explained by the 'spreading of risk' hypothesis (den Boer 1968). According to this concept, the 'spreading of risk' of over asynchronously fluctuating 'interaction groups' ('subpopulations') significantly increases the chance of survival of the population as whole. With respect to larger species, distances of about $50 \mathrm{~m}$ between the traps may be too short to guarantee independent samples. On the other hand, in Waltrop the traps 5, 16, 18 and 23 were at least $100 \mathrm{~m}$ apart, and the numbers of individuals of $P$. versicolor, for example, fluctuated asynchronously at these traps (Fig. 3). However, the degree of asynchronicity may differ between different species, as demonstrated for $P$. versicolor and C. melanocephalus by den Boer (1981). Data elaborated for these species in the present study corroborate these results. Moreover, changes in the stage of succession may affect the fluctuation patterns of 'interaction groups' ('subpopulations'), as proposed for Pterostichus oblongopunctatus (Fabricius, 1787) by Szyszko et al. (1996).

Our results have some practical implications. First, as stated by Hanski (1998), plots currently not occupied by a given species may be of importance for the long-term persistence of that species. This is of special importance for species assessed to be rare. For example, A. praetermissa is in the red list of Germany (Trautner et al. 1997) as being critically endangered, and in the red list of North-Rhine Westphalia (Schüle \& Terlutter 1998) as being at the brink of extinction. Moreover, because patterns of population dynamics may change for the species with the ongoing of a succession, special attention has to be paid to stages of succession. Moreover, a coexistence of different successional stages in a given area may contribute to species diversity, thereby increasing large-scale carabid richness, as many species are almost exclusively connected to special stages of succession (e.g., Assmann 1999, Pizzolotto et al. 2005).

Acknowledgements. The authors thank the Ruhrkohle Bergbau AG for their financial support of the study on the colliery spoil heap Waltrop, and Dipl. Biol. Karsten Hanning for confirming the identifications of difficult individuals. Matti Koivula and two anonymous referees significantly improved an earlier draft of the manuscript. This paper is communication nr. 140 of the Laboratory of Evaluation and Assessment of Natural Resources, Warsaw Agricultural University.

\section{References}

Assmann, T. 1999: The ground beetle fauna of ancient and recent woodlands in the lowlands of north-west Germany (Coleoptera, Carabidae). - Biodiversity and Conservation 8: 1499-1517.

Bradshaw, A. D. 1984: Ecological principles and land reclamation practice. - Landscape Planning 11:35-48.

den Boer, P. J. 1968: Spreading of risk and stabilization of animal numbers. - Acta Biotheoretica 18: 165-194.

den Boer, P. J. 1977: Dispersal power and survival. Carabids in a cultivated countryside. - Miscellaneous Papers, LH Wageningen 14. $190 \mathrm{pp}$.

den Boer, P. J. 1981: On the survival of populations in a heterogeneous and variable environment. - Oecologia (Berlin) 50: 39-53.

den Boer, P. J. \& Reddingius, J. 1996: Regulation and stabilization paradigms in population ecology. - Chapman \& Hall. 397 pp.

Freude, H., Harde, K.-W., Lohse, G. A. \& Klausnitzer, B. 2004: Die Käfer Mitteleuropas. Bd. 2, Adephaga 1, Carabidae (Laufkäfer), 2. (erweiterte) Aufl. — Spektrum-Verlag (Heidelberg/Berlin). 521 pp.

Hanski, I. 1998: Metapopulation dynamics. - Nature 396: 41-49. 
Hanski, I. \& Gilpin, M. 1991: Metapopulation dynamics: brief history and conceptual design. - Biological Journal of the Linnean Society 42: 3-16.

Hatteland, B. A., Hauge, E., Kirkendall, L. R. \& Solhřy, T. 2005: Diversity and habitat preferences of ground beetles (Coleoptera, Carabidae) in a coastal area of North Trřndelag, Central Norway. - DIAS report, No. 114: $125-135$.

Holm, S. 1979: A simple sequentially rejective multiple test procedure. - Scandinavian Journal of Statistics 6: $65-70$.

Jaccard, P. 1902: Lois de distribution florale dans la Zone alpine. - Bulletin Société Vaudoise des Sciences Naturelles 38: 69-130. [In French.]

Jochimsen, M. E. 2001: Vegetation development and species assemblages in a long-term reclamation project on mine spoil. - Ecological Engineering 17: 187-198.

Magura, T. 2002: Carabids and forest edge: spatial pattern and edge effect. - Forest Ecology and Management 157: $23-37$.

Neumann, U. 1971: Die Sukzession der Bodenfauna (Carabidae [Coleoptera], Diplopoda und Isopoda) in den forstlich rekultivierten Gebieten des Rheinischen Braunkohlenreviers. - Pedobiologia 11: 193-226.

Pizzolotto, R., Brandmayr, P. \& Mazzei, A. 2005: Carabid beetles in a Mediterranean Region: biogeographical and ecological features. - DIAS Report 114: 243 254.

Sachs, L. 1984: Angewandte Statistik: Anwendung statistischer Methoden, 6th ed. - Springer, Berlin-Heidelberg-New York-Tokyo. 552 pp.

Schüle, P. \& Terlutter, H. 1998: Rote Liste der in Nordrhein-Westphalen gefährdeten Sandlaufkäfer und Laufkäfer, - Angewandte Carabidologie 1: 51-62.
Schwerk, A., Geiss, O., Erfmann, M. \& Abs, M. 2004: Multivariate analysis of a long-term study on carabid beetles (Coleoptera: Carabidae) on a colliery spoil heap in the Ruhr Valley Area. - Baltic Journal of Coleopterology 4: 13-22.

Szyszko, J. 1983: Methods of macrofauna investigations. - In: Szujecki, A., Mazur, S., Perliński, S. \& Szyzsko, J. (eds.), The process of forest soil macrofauna formation after afforestation of farmland: 10 16. Warsaw Agricultural University Press, Warsaw. $196 \mathrm{pp}$.

Szyszko, J., Vermeulen, H. J. W. \& den Boer, P. J. 1996: Survival and reproduction in relation to habitat quality and food availability for Pterostichus oblongopunctatus F. (Carabidae, Col.). - Acta Jutlandica 71: $25-40$.

Szyszko, J., Vermeulen, H. J. W., Klimaszewski, K., Abs, M. \& Schwerk, A. 2000: Mean individual biomass (MIB) of ground beetles (Carabidae) as an indicator of the state of the environment. - In: Brandmayr, P., Lövei, G., Zetto Brandmayr, T., Casale, A. \& Vigna Taglianti, A. (eds.), Natural history and applied ecology of carabid beetles: 289-294. Pensoft Publishers, Sofia-Moscow. 304 pp.

Tilman, D. 1987: Secondary succession and the pattern of plant dominance along experimental nitrogen gradients. - Ecological Monographs 57: 189-214.

Trautner, J., Müller-Motzfeld, G. \& Bräunicke, M. 1997: Rote Liste der Sandlaufkäfer und Laufkäfer Deutschlands, 2. Fassung, Stand Dezember 1996. Naturschutz und Landschaftsplanung 29: 261-273.

Vuong, V. 1989: Anlass und Zielsetzung des Forschungsprojektes auf der Halde Waltrop. - Mitteilungen Deutsche Bodenkundliche Gesellschaft 58: 207. 
Appendix. Carabids caught in Waltrop (1991-1994, 1996, 2000) and in Krzywda (2004 only) sorted by total abundance (Sum).

Species

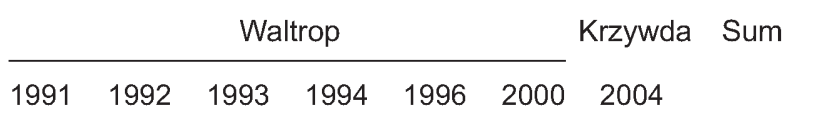

Poecilus versicolor (Sturm, 1824)

Calathus fuscipes (Goeze, 1777)

Harpalus affinis (Schrank, 1781)

Amara lunicollis Schiödte, 1837

Calathus melanocephalus (Linné, 1758)

Harpalus rubripes (Duftschmid, 1812)

Nebria salina Fairmaire \& Laboulbène, 1854

363

Trechus quadr. (Schrank, 1781) / obt.

Erichson, 1837

Pterostichus melanarius (Illiger, 1798)

Harpalus rufipes (De Geer, 1774)

Harpalus tardus (Panzer, 1796)

Pterostichus niger (Schaller, 1783)

Amara aenea (De Geer, 1774)

Harpalus distinguendus (Duftschmid, 1812)

Amara bifrons (Gyllenhal, 1810)

Carabus nemoralis O. F. Müller, 1764

Amara communis (Panzer, 1797)

Calathus erratus (C. R. Sahlberg, 1827)

Nebria brevicollis (Fabricius, 1792)

Anisodactylus binotatus (Fabricius, 1787)

Poecilus cupreus (Linné, 1758)

Synuchus vivalis (Illiger, 1798)

Syntomus truncatellus (Linné, 1761)

Ophonus puncticeps Stephens, 1828

Lionychus quadrillum (Duftschmid, 1812)

Amara aulica (Panzer, 1797)

Pterostichus vernalis (Panzer, 1796)

Amara plebeja (Gyllenhal, 1810)

Bembidion tetracolum Say, 1823

Bradycellus csikii Laczó, 1912

Amara eurynota (Panzer, 1797)

Poecilus lepidus (Leske, 1785)

Notiophilus biguttatus (Fabricius, 1779)

Syntomus foveatus (Geoffroy, 1785)

Dyschirius globosus (Herbst, 1784)

Amara praetermissa (C. R. Sahlberg, 1827)

Clivina fossor (Linné, 1758)

Bradycellus harpalinus (Audinet-Serville, 1821)

Amara convexior Stephens, 1828

Notiophilus palustris (Duftschmid, 1812)

Pterostichus strenuus (Panzer, 1796)

Amara similata (Gyllenhal, 1810)

Notiophilus substriatus Waterhouse, 1833

Amara familiaris (Duftschmid, 1812)

Bembidion quadrimaculatum (Linné, 1761)

Bembidion lampros (Herbst, 1784)

Harpalus luteicornis (Duftschmid, 1812)

Panagaeus bipustulatus (Fabricius, 1775)

Agonum muelleri (Herbst, 1784)

Abax parallelepipedus (Piller \& Mitterpacher, 1783)

Bradycellus verbasci (Duftschmid, 1812)

Harpalus smaragdinus (Duftschmid, 1812)

Oodes helopioides (Fabricius, 1792)

Anchomenus dorsalis (Pontoppidan, 1763)

Carabus granulatus Linné, 1758

Notiophilus aquaticus (Linné, 1758)

$\begin{array}{rrrrrr}201 & 102 & 78 & 166 & 226 & 1,782 \\ 309 & 323 & 106 & 39 & 156 & 1,756 \\ 73 & 115 & 28 & 31 & 16 & 1,052 \\ 150 & 74 & 15 & 13 & 12 & 882 \\ 54 & 57 & 23 & 6 & 104 & 799 \\ 55 & 34 & 32 & 37 & 320 & 767 \\ 89 & 174 & 79 & 118 & - & 703\end{array}$

$140 \quad 103$

$105 \quad 119$

$11 \quad 120$

$52 \quad 48$

- 1

$9 \quad 14$

$11 \quad 22$

$139 \quad 65$

11323

$26 \quad 61$

$\begin{array}{lll}69 & 75 \quad 26\end{array}$

27

54

12

$11 \quad 16$

22

2
21

32

$\begin{array}{rr}3 & 18 \\ 3 & 4\end{array}$

96

$11 \quad 12$

932

2

28

76

24

39

20

31

38

56

66

5
12

$-$

15

7
17

22

5

29

6

6
6

2
14

- 18

$$
27
$$

4

5

22

48

30

44

14
17

16

16
6

4
20

5

15

11

19

8

13

5
18

17

1

151

160

267

168

102

-

23

6

6
11
157

157

20

7

16

3

2

20

$-$

$$
3
$$

$$
\begin{aligned}
& 4 \\
& 1 \\
& 6
\end{aligned}
$$$$
\text { . }
$$$$
-
$$

$$
\text { - }
$$$$
3
$$$$
1
$$$$
14
$$$$
11
$$$$
10
$$ 
Asaphidion flavipes (Linné, 1761)

Badister bullatus (Schrank, 1798)

Bembidion stephensii Crotch, 1869

Harpalus latus (Linné, 1758)

Leistus terminatus (Hellwig in Panzer, 1793)

Loricera pilicornis (Fabricius, 1775)

Calathus rotundicollis Dejean, 1828

Cychrus caraboides (Linné, 1758)

Harpalus griseus (Panzer, 1796)

Pterostichus minor (Gyllenhal, 1827)

Notiophilus rufipes Curtis, 1829

Agonum sexpunctatum (Linné, 1758)

Calathus cinctus Motschulsky, 1850

Agonum fuliginosum (Panzer, 1809)

Amara consularis (Duftschmid, 1812)

Amara equestris (Duftschmid, 1812)

Harpalus pumilus Sturm, 1818

Harpalus rufipalpis Sturm, 1818

Leistus rufomarginatus (Duftschmid, 1812)

Microlestes minutulus (Goeze, 1777)

Pterostichus diligens (Sturm, 1824)

Pterostichus oblongopunctatus (Fabricius, 1787)

Stenolophus mixtus (Herbst, 1784)

Acupalpus meridianus (Linné, 1761)

Badister lacertosus Sturm, 1815

Carabus hortensis Linné, 1758

Carabus violaceus Linné, 1758

Cymindis angularis Gyllenhal, 1810

Harpalus anxius (Duftschmid, 1812)

Paradromius linearis (Olivier, 1795)

Pterostichus nigrita (Paykull, 1790)

Trichocellus placidus (Gyllenhal, 1827)

Agonum emarginatum (Gyllenhal, 1827)

Agonum gracilipes (Duftschmid, 1812)

Amara apricaria (Paykull, 1790)

Amara cursitans Zimmermann, 1832

Amara curta Dejean, 1828

Amara lucida (Duftschmid, 1812)

Amara spreta Dejean, 1831

Amara tibialis (Paykull, 1798)

Badister unipustulatus Bonelli, 1813

Bembidion milleri Jacquelin du Val, 1852

Bembidion properans (Stephens, 1828)

Bradycellus caucasicus (Chadoir, 1846)

Broscus cephalotes (Linné, 1758)

Carabus arvensis Herbst, 1784

Carabus cancellatus Illiger, 1798

Clivina collaris (Herbst, 1784)

Demetrias atricapillus (Linné, 1758)

Dolichus halensis (Schaller, 1783)

Philorhizus melanocephalus (Dejean, 1825)

Elaphrus cupreus Duftschmid, 1812

Harpalus picipennis (Duftschmid, 1812)

Harpalus signaticornis (Duftschmid, 1812)

Lebia chlorocephala (J.J. Hoffmann et al., 1803)

Masoreus wetterhallii (Gyllenhal, 1813)

Ophonus azureus (Fabricius, 1775)

Patrobus atrorufus (Stroem, 1768)

Pterostichus gracilis (Dejean, 1828)

Stomis pumicatus (Panzer, 1796)

Elaphropus parvulus (Dejean, 1831) 